\title{
STUDY AND COMPARATIVE ANALYSIS OF RESONAT FREQUENCY FOR MICROSRTIP FRACTAL ANTENNA
}

\author{
Naveen Upadhyay ${ }^{1}$, Naveen Hemrajani ${ }^{2}$, Sandhya Sharma ${ }^{3}$, Rashid Hussain ${ }^{4}$ \\ ${ }^{1}$ M. Tech. Scholar, ${ }^{3}$ Associate Professor, ${ }^{4}$ Head of Department, Department of ECE, SGV University, Rajasthan, India \\ 2 Principal, GVSET, SGV University, Rajasthan, India, \\ naveen.sgvu@gmail.com,naveen.h@gyanvihar.org, sandhya.mbm@gmail.com,hussain1992@gmail.com
}

\begin{abstract}
A new compact fractal patch antenna is designed based on the fractal geometry. Based on the simulation results, the proposed antenna has shown an excellent size reduction possibility with good radiation performance for wireless communication applications. The change in resonating frequency with respect to the dielectric constant of substrate has shown and discussed in this paper. The various resonating frequencies for designed antenna are $8.59 \mathrm{GHz}, 9.2 \mathrm{GHz}$ and $11.36 \mathrm{GHz}$ for RT Duroid Rogers 6010 , FR 4 and RT Duroid Rogers 5880 respectively. The S-parameter $\left(S_{11}\right)$ for resonating frequencies is well below -10 dB. The far-field patternand $S_{11}$ oftheproposedantennaissimulatedandanalyzedusingCST Microwave Studio 2011
\end{abstract}

Index Terms: Microstrip antenna, Fractal antenna, Multiband antenna, and Plusses geometry

\section{INTRODUCTION}

In high performance spacecraft, aircraft and satellite applications where weight, size, ease of installation, cost, and performance highly required and low-profile antennas would be required. Presently there are many other applications like mobile radio and wireless communications that have similar specifications. To meet these requirements, micro strip patch antennas can be used[1].These antennas are low profile, conform able to non-planar surfaces and planar surfaces, simple and affordable to design using modern printed-circuit technology, mechanically shouldered when mounted on rigid surfaces, compatible with MMIC designs, and when the particular patch shape and mode are selected, they are very various in terms of resonant frequency, radiation pattern. There has been an ever growing demand, in both the military as well as the commercial sectors, for antenna design that features the following highly desirable evaluate:
i) Tiny Size
ii) Low profile
iii) Conformal
iv) Broadband or multiband

The useof plusses fractal geometry isa solution to the design of broadband antennas. Theterm fractal,which means brokenorirregular fragments, wasoriginallyproposed byMandelbrot [2] to describea familyof complex shapes thatfeatures selfsimilarity intheirgeometricalstructure.The original inspiration for thedevelopment of fractal geometry came due tothe patterns of nature. For instance, fractals have been successfully usedto model suchcomplex natural objects such as cloudboundaries,coastlines, snowflakes,mountains, trees.Leavesand much morevariety of applicationsfor fractals continue tobe foundin many branches of science and engineering[3].Modern telecomm systems requireantennas with smallerdimensions and wider $\mathrm{BW}$ than conventionally available antennas.Fractal antenna was first researchin various directions, one ofwhichisby using fractal shaped antenna elements.Inrecentyears several fractal geometrieshave beenintroducedforantennaapplications with varying degrees of successinimprovingantenna characteristics. Some ofthese geometrieshavebeen particularly useful in reducingthesizeof theantenna,whileotherdesignsaim atincorporating multi-bandcharacteristics. Theseare low profileantennaswith moderategain and canbe made operative at multiple frequency bands andhence are multi- functional.

\section{GENERATION OF PLUSSES FRACTAL}

\section{ANTENNA}

Fractal are basically geometrical shapes that are designed by a very easy to construct pattern that becomes more congested as we repeat and apply the same rule of first phase of fractal geometry. In many cases, the rules change the original figure by adding or removing parts of the figure. This process is repeated an unlimited number of times. One of the simplest fractal to visualize and work with mathematically is the Plusses fractal. This process starts with a + sign and add plus signs that are half sixe to each of the four line ends. The Fig.-1 shows the how the Plusses fractal determines after 2 iteration. Note that how the + sign changes into diamond. 


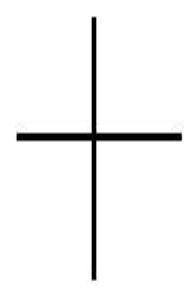

Iteration 0
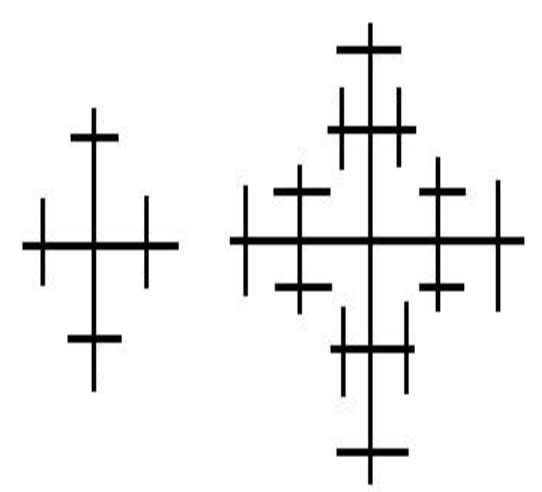

Iteration 2
Fig-1: Iteration of Construction of plusses fractal geometry

The side length of the zero iteration plusses fractal antenna, L0 can be explained as:

$$
\mathrm{L} 0=2 \mathrm{a}
$$

Where $\mathrm{a}$ is the length of each arm in the plusses fractal geometry.

For the nth iteration, it will be found that, the side length of the plusses fractal antenna

$$
\mathrm{Ln} \text { is } \mathrm{Ln}=\mathrm{L}(\mathrm{n}-1)+\mathrm{a} / 2(\mathrm{n}-1), \text { for } \mathrm{n}>0
$$

\section{DESIGN AND SIMULATION OF PROPOSED}

\section{ANTENNA}

Aseconditeration

of

plussesfractalantenna withpairsofcoaxialfeedsat $\mathrm{x}=3 \mathrm{mmand}=3 \mathrm{~mm}$ isshowninFig2,and usingsubstrateFR4 Lossy ( $\varepsilon r=4.3)$, RT Rogers 5880 Lossy ( $\varepsilon r=2.2)$ and RT Rogers 6010 Lossy ( $\varepsilon r=10.2)$ witha substrate heighth $=1.6$ mmandthe dimensions of the dielectric layer are 18 x $18 \mathrm{~mm} 2$. Inthiswork, CST Microwave Studio 11 isused toanalyze adetailedstudy of resonant frequency,returnloss (S11), andradiationfieldpattern of the proposedplussesfractal antenna based on the dielectric coefficient (cr) of substrate material. As we know that dielectric constant ( $\varepsilon r$ ) of substrate and substrate height plays a vital role in any antenna. So we have studied about the three different substrates i.e. RT Rogers 5880 (Lossy), FR 4 (Lossy) and RT Rogers 6010 (Lossy) for the same dimension of designed antenna.

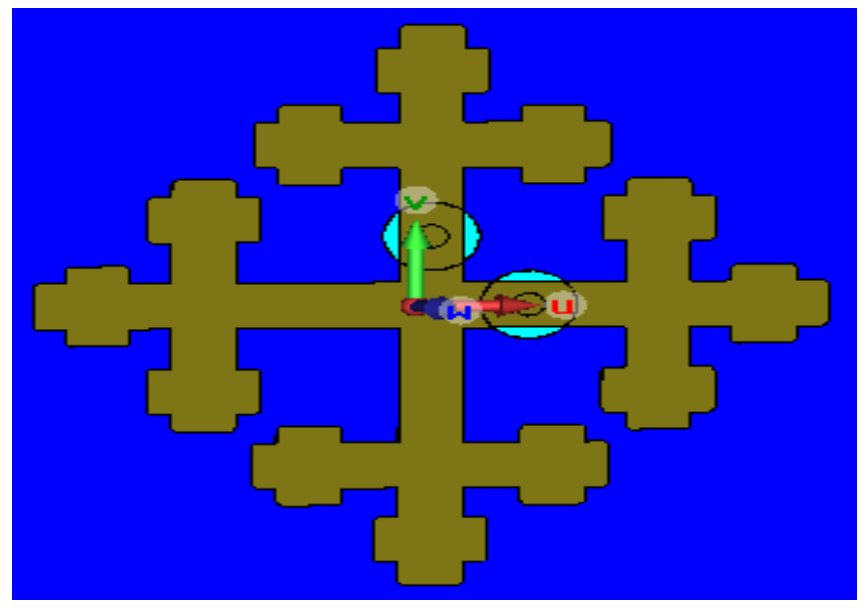

Fig 2: 2- Dimensional (2D) view of Proposed Fractal Antenna

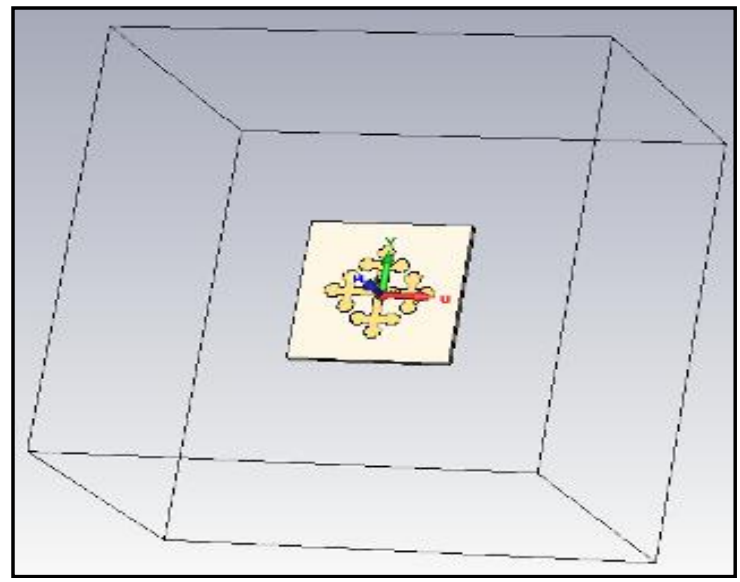

Fig 3: 3- Dimensional (3D) view of Proposed Fractal Antenna

In this paper we simulated fractal antenna using CST Microwave Studio 2011. In the beginning process of study we design a fractal antenna with the following dimensions shown in Table- 1

\begin{tabular}{|l|l|}
\hline Coax Length & $3 \mathrm{~mm}$ \\
\hline Coax Outer Diameter & $3 \mathrm{~mm}$ \\
\hline Substrate Half Length & $18 \mathrm{~mm}$ \\
\hline Probe Diameter & $1 \mathrm{~mm}$ \\
\hline Fractal Length 1st Iteration & $12.25 \mathrm{~mm}$ \\
\hline Blend Radius & $0.2 \mathrm{~mm}$ \\
\hline Fractal Thickness & $0.0175 \mathrm{~mm}$ \\
\hline Substrate Height & $1.6 \mathrm{~mm}$ \\
\hline Feed Location in x- direction & $3 \mathrm{~mm}$ \\
\hline Branch Distance form Centre & $6 \mathrm{~mm}$ \\
\hline
\end{tabular}




\begin{tabular}{|l|l|}
\hline Branch 2 distance form Centre & $9.25 \mathrm{~mm}$ \\
\hline Branch 3 extra width & $0.75 \mathrm{~mm}$ \\
\hline Feed Location in y- direction & $3 \mathrm{~mm}$ \\
\hline Branch 1 half Length & $11 \mathrm{~mm}$ \\
\hline Branch 2 half Length & $3.5 \mathrm{~mm}$ \\
\hline Branch 3 distance from Centre & $2.75 \mathrm{~mm}$ \\
\hline Fractal Half Width & $1 \mathrm{~mm}$ \\
\hline Substrate Half Width & $18 \mathrm{~mm}$ \\
\hline
\end{tabular}

Table- 1: Dimensions of proposed antenna

\subsection{For substrate RT Rogers 5880}

When we use substrate material RT Rogers Duroid 5880 which have dielectric constant $\varepsilon r=2.2$, after designing the proposed antenna, S11 parameter shows that the resonant frequency is $11.36 \mathrm{GHz}$. Figures of S11 Parameter and Far field Radiation pattern (3D \& Polar) are shown in Fig.- 4, 5 and 6 respectively

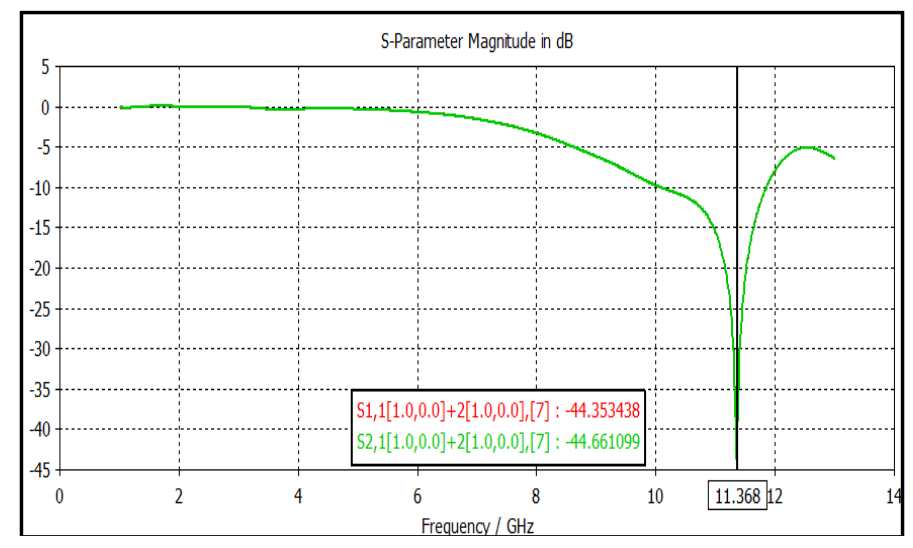

Fig 4: S11 Parameter when Substrate is RT 5880

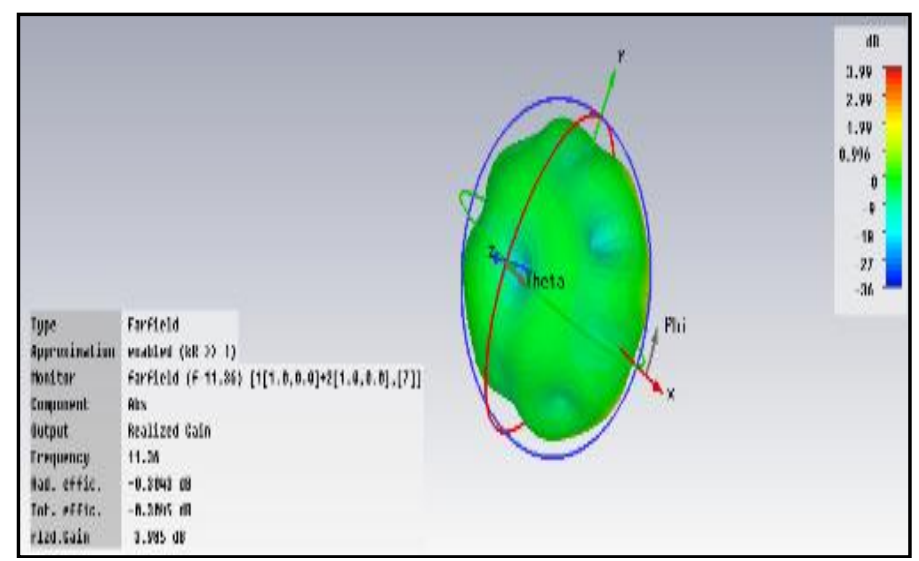

Fig 5: Far field pattern 3D

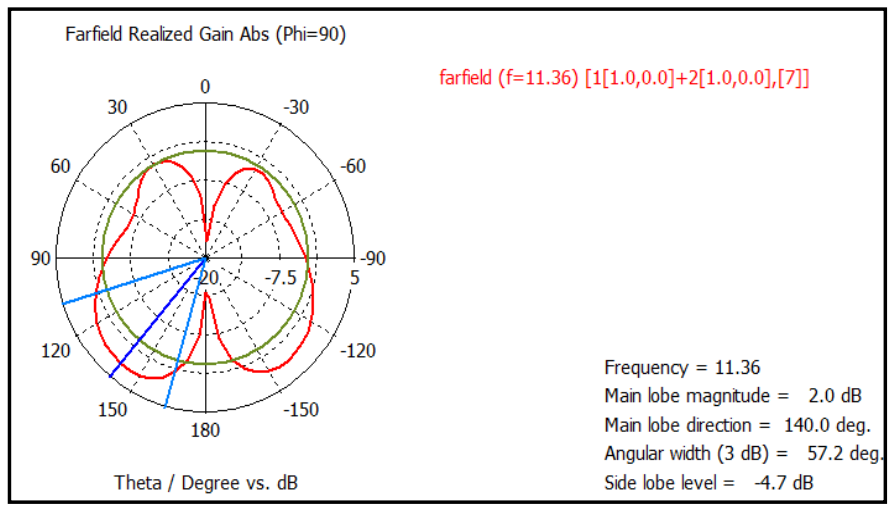

Fig 6: Far field pattern (Polar)

\subsection{For substrate FR 4}

When we use substrate material FR 4 which have dielectric constant $\varepsilon r=4.3$, after designing the proposed antenna, S11 parameter shows that the resonant frequency is $9.2 \mathrm{GHz}$. Figures of S11 Parameter and Far field Radiation pattern (3D \& Polar) are shown in Fig.7, 8 and 9 respectively.

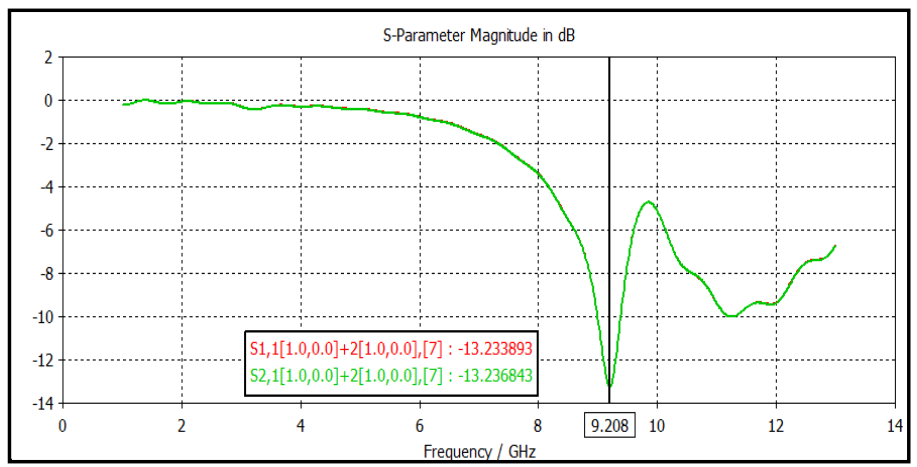

Fig- 7: S11 Parameter when Substrate is FR 4

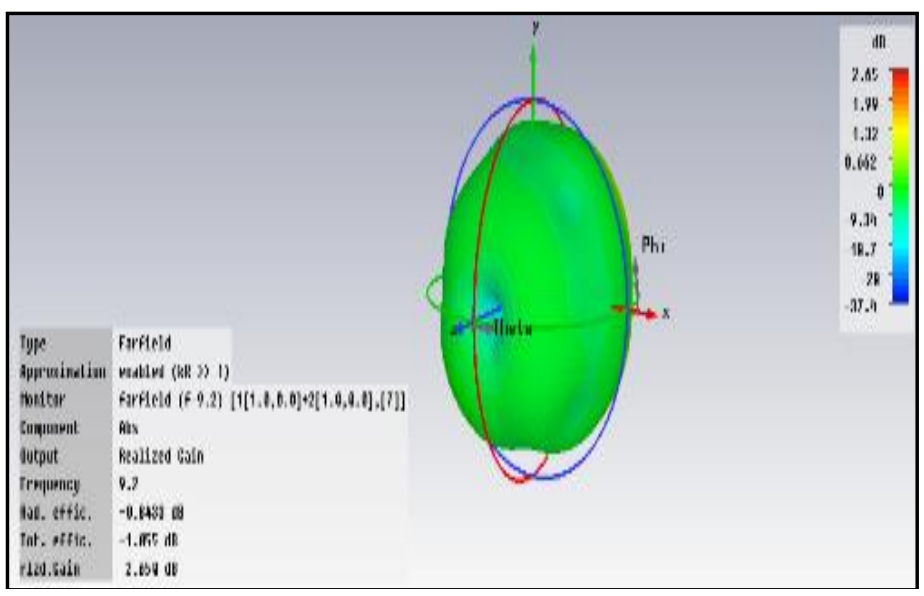

Fig 8: Far field pattern 3D 


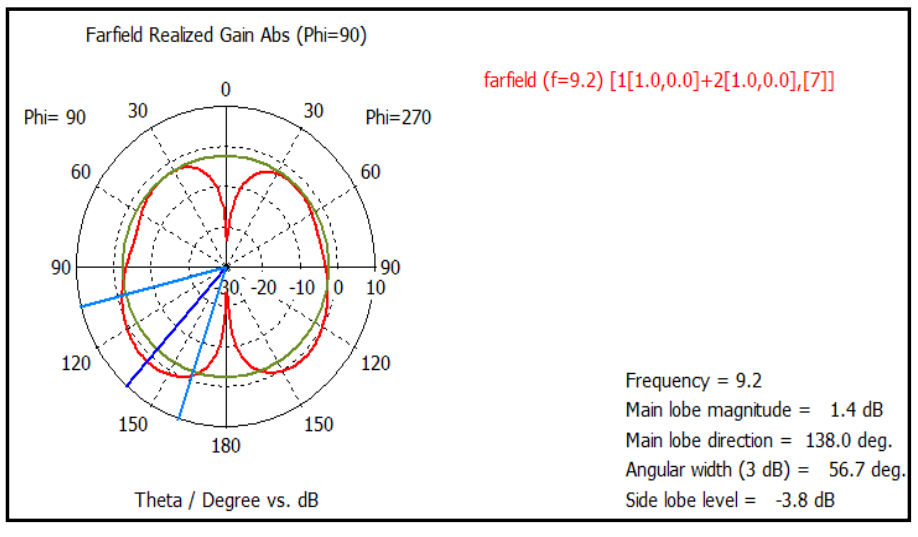

Fig 9: Far Field pattern (Polar)

\subsection{For substrate RT Rogers 6010}

When we use substrate material RT Rogers Duroid 6010 which have dielectric constant $\varepsilon r=10.2$, after designing the proposed antenna, S11 parameter shows that the resonant frequency is $8.59 \mathrm{GHz}$. Figures of S11 Parameter and Far field Radiation pattern (3D \& Polar) are shown in Fig.10, 11 and 12 respectively

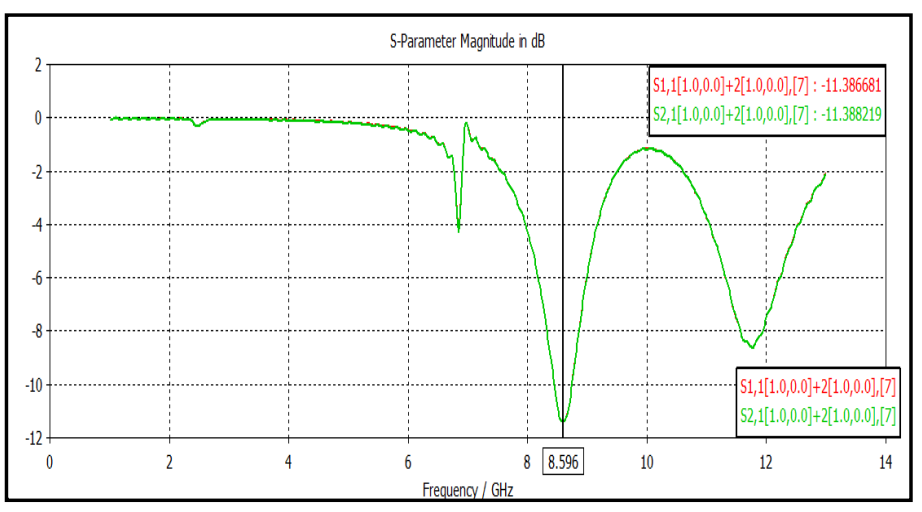

Fig 10: S11 Parameter when Substrate is RT 6010

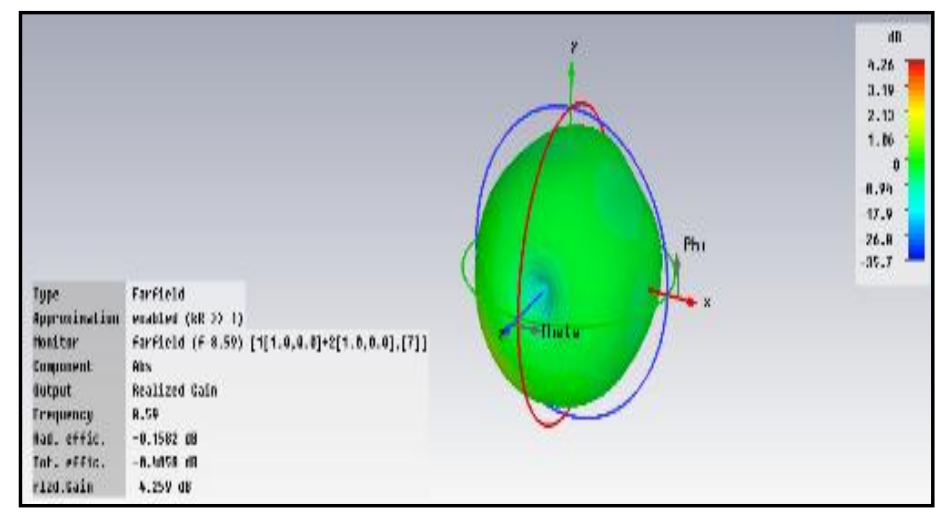

Fig 11: Far field pattern 3D

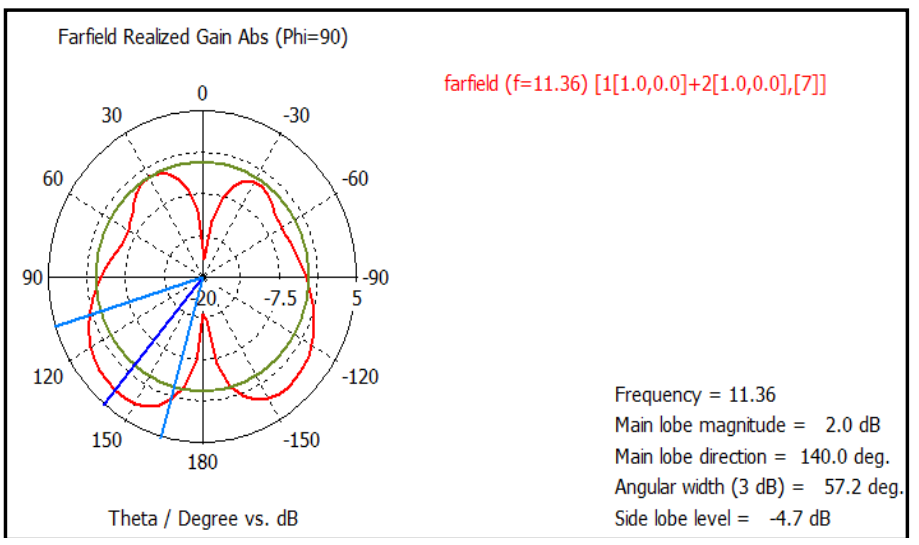

Fig 12: Far Field pattern (Polar)

\subsection{Simulation Results}

Simulation results of all the three substrate materials are shown in Table- 2

Table- 2: Simulation results

\begin{tabular}{|l|l|l|l|l|}
\hline Substrate & $\varepsilon r$ & $\begin{array}{l}\text { S11 } \\
(\mathrm{dB})\end{array}$ & $\begin{array}{l}\text { Resonant } \\
\text { Frequency } \\
(\mathrm{GHz})\end{array}$ & $\begin{array}{l}\text { Realized } \\
\text { Gain(dB } \\
)\end{array}$ \\
\hline RT 5880 (Lossy) & 2.2 & -44.35 & 11.36 & 3.985 \\
\hline FR 4 (Lossy) & 4.3 & -13.23 & 9.2 & 2.650 \\
\hline RT 6010 (Lossy) & 10.2 & -11.38 & 8.59 & 4.259 \\
\hline
\end{tabular}

\section{CONCLUSIONS}

The main aim of this paper is that, when we choose the substrate with lower Dielectric constant then the resonant frequency is higher in the appropriate frequency band of corresponding antenna. The table- 2 suggests that when dielectric constant (er ) is low than Resonant Frequency is high. Plusses Fractal antenna simulation has given expected results in terms of S11, resonant frequency and realized gain. The antenna presented can be used in multiband wireless communication, indoor wirelesses i.e. Wi-Fi, WiMax, RFID, medical instruments, sensors, aerospace and in many more areas of application.

\section{ACKNOWLEDGEMENTS}

The authors would like to thanks to Dr. B. N. Rao, Hon'ble Vice Chancellor, Suresh GyanVihar University, Jaipur and Dr. P.B.L. Chaurasia, Dean- Engineering, Suresh GyanVihar University, Jaipur for his continuous support and encouragement. 


\section{REFERENCES}

[1]. Balanis C. A. 2005. Antenna Theory: Analysis and Design. 3rd Ed. Wiley

[2]. B. B. Mandelbort. 1983. The FractalGeometryof

Nature, W. H.Freeman

[3]. WernerD.H. andGanguly S. 2003. AnOverview of Fractal Antenna Engineering Research, IEEE Antennas andPropagation Magazine.45(1): 38-57

\section{BIOGRAPHIES:}

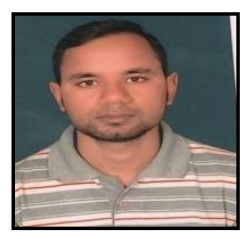

Naveen Upadhyaydid his B.E. in ECE from University of Rajasthan, Jaipur in 2009. He is pursuing his M.Tech in DWCE from SGV University, Jaipur- Rajasthan. $\mathrm{He}$ is a member of IEEE Communication Society. His area of interest are antennas, mobile communication etc.

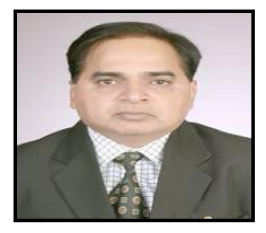

Naveen Hemrajani, (M.Tech., Ph.D.) presently is working as Principal, GVSET, SGV University, Jaipur- Rajasthan. He is having 21 years experience in teaching and research. His area of interest is Network Simulator, Computer Science and etc.

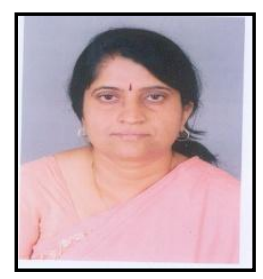

Sandhya Sharmadid her B.E. from GEC, Raipur in 1996 and M.E. from MBM Engineering College, Jodhpur in 2006 in ECE. Presently she is working as an Associate Professor in ECE Department, SGV University. She is having 11 Years of teaching experience. Her area of interest is communication etc. optical communication, ITC and Mobile

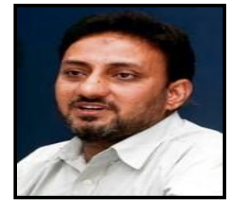

Rashid Hussain, B.Tech, M.Tech. and Ph.D.(pursuing) presently working as HOD, Department of ECE, SGV University, Rajasthan. He is having experience in Infosys Technologies Ltd for 7 Years and 7 years of teaching experience. His area of interest is wireless sensor networks, networking and etc. 